\title{
Study of in vitro and in vivo free radical scavenging activity for radioprotection of cerium oxide nanoparticles
}

\author{
Asia H. Al-Mashhadani and Rana M. Yas \\ Department of Physics, College of Science, University of Baghdad \\ E-mail: assia19662006@yahoo.com
}

\begin{abstract}
Nanoceria have shown numerous unique characteristics, such as biocompatibility and are excellent agents for biological applications. The aim of this study is to investigate cerium oxide nanoparticles for 2, 2- diphenyl-1-picryl-hydrazyl-hydrate (DPPH) free radical scavenging activity and their ability to offer protection against ionizing radiation. In vitro antioxidant activity study of nanoceria particles has shown good free radical scavenging activity for DPPH radical assayed within a concentration range of 0.01 to $0.05 \mathrm{~g} / \mathrm{l}$, at higher concentrations of nanoparticles showed reverse trend in absorbance and inhibition indicating this finite rang of concentration is suitable for scavenging free radicals, also nanoparticles were found to have significant antioxidant capacity and thus can be used as potential radical scavenger against deleterious damages caused by the free radicals. The results of histopathological examination showed effectiveness of $\mathrm{CeO}_{2}$ nanoparticles in radioprotection of skin cells in animal models during radiation exposure.
\end{abstract}

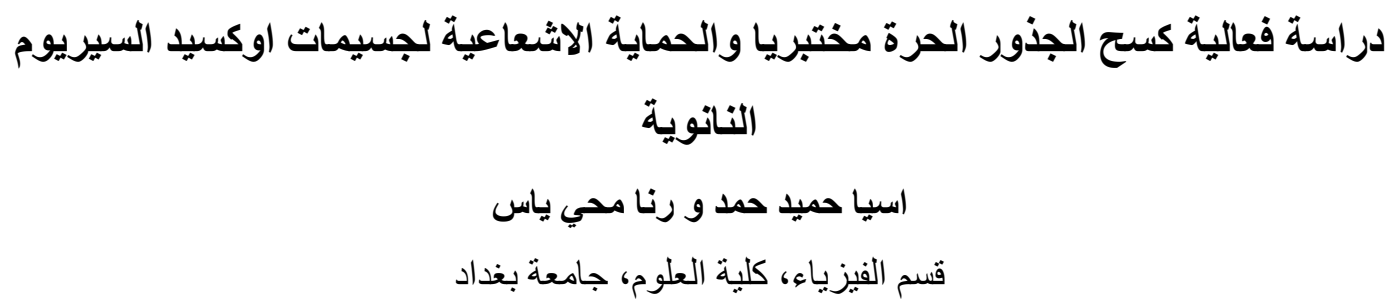

Key words

Cerium oxide

nanoparticles, DPPH

radical scavenging

activity, radiation

protection.

Article info.

Received: May. 2016

Accepted: May. 2016

Published: Dec. 2017

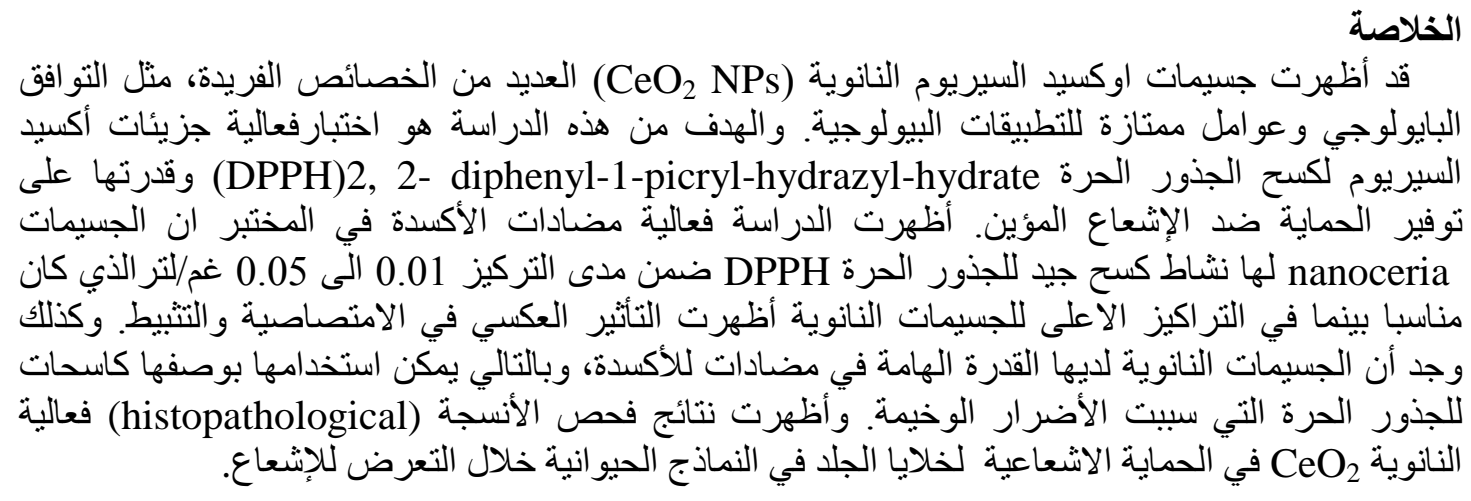

الخلاصة

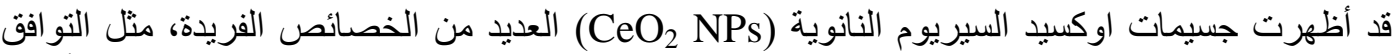

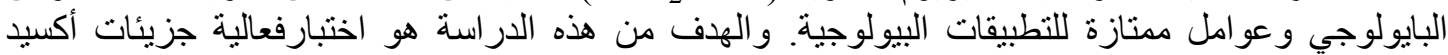

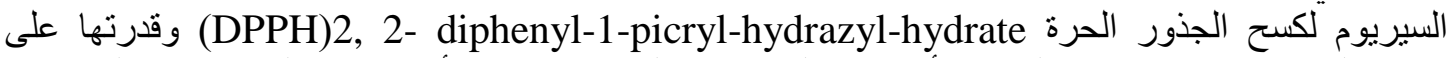

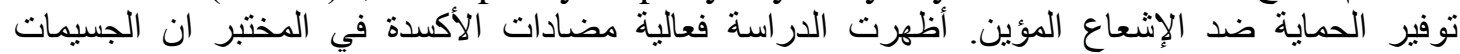

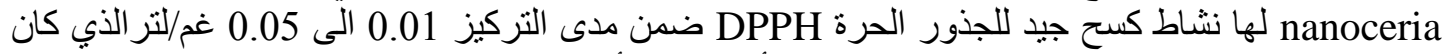

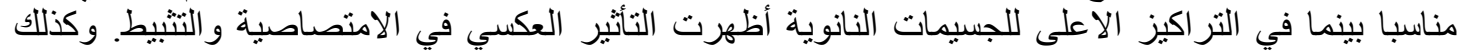

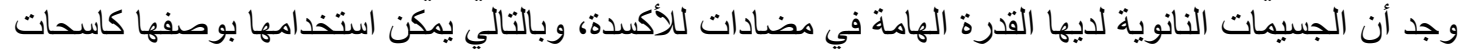
للجذور الحرة التي سبيت الأضرار الوخيمة. وأظهرت نتائج فحص الأنسجة (histopathological) فعالية النانوية $\mathrm{CeO}_{2}$ في الحماية الاشعاعية لخلايا الجلد في النماذج الحيو انية خلال التعرض للإنشعاع.

\section{Introduction}

Living organisms are continuously exposed to ionizing radiations from natural radiation. In addition, exposures occur as a result of human activities and medical practices. Radiations are broadly categorized into natural and man-made sources. Manmade radiation exposure to populations occurs mainly from medical uses of radiation and radioisotopes in health care. Use of ionizing radiation in medical diagnosis and therapy is widespread and constantly increasing 
due to useful newer health care applications. Ionizing radiation may be divided into directly and indirectly ionizing for the understanding of biological effects [1]. Electromagnetic radiations, $\mathrm{x}$ and $\gamma$ rays, are indirectly ionizing because they do not produce chemical and biological damage themselves but produce secondary electrons (charged particles) after energy absorption in the material.

Ionizing radiation causes damage to living system through a series of molecular events, such as photoelectric, Compton and Auger effects, depending on the radiation energy. Since the predominant molecule in biological systems is water, it is usually the intermediary of the radical formation and propagation. The major radiation damage is due to the aqueous free radicals, generated by the action of radiation on water. A free radical is an electrically neutral atom with an unshared electron in the orbital position, where the radical is highly reactive [2].

When radiation interacts with target atoms, energy is deposited, resulting in ionization or excitation. The absorption of energy from ionizing radiation produces damage to molecules by direct and indirect actions. For direct action, damage occurs as a result of ionization of atoms on key molecules in the biologic system. This causes inactivation or functional alteration of the molecule. Indirect action involves the production of reactive free radicals whose toxic damage on the molecule results in a biologic effect [3]. The radicals formed after passage of radiation and water radiolysis, namely the hydrated electron (eaq -), the hydrogen atom $\left(\mathrm{H}^{\cdot}\right)$ and the hydroxyl radical $\left(\mathrm{OH}^{\prime}\right)$ contribute in causing damage to biological systems [4]. Protection against ionizing radiation is of serious importance during accidental and unavoidable exposures to radiation and development the effective approaches to reduce radiation damages using non-toxic radioprotectors are of considerable interest for defense, nuclear industries, radiation accidents, space travels, etc., besides the protection of normal tissues during radiotherapy of tumours and medical diagnostic exposures [5].

Nowadays it is a growing interest in the development of nanotechnology, the science which deals with the creation, production, characterization and manipulation of materials at the nanoscale $[6,7]$. Nano-sized materials, known as nanoparticles, possess unique and improved properties because of their larger surface area to volume ratio and are considered building blocks of nanotechnology to design materials with interesting properties [8].

Cerium is a rare earth metal belonging to the lanthanide series. In the nanoparticle formulation, cerium combined with oxygen and adopts a fluorite crystalline structure that has unique antioxidant properties $[9,10]$ derived from the kinetics and thermodynamics of the redox processes on the nanoparticle surface. Cerium can shift between $\mathrm{Ce} 4+$ and $\mathrm{Ce} 3+$ states under oxidizing and reducing conditions by reversibly binding with oxygen. The loss of oxygen and the reduction of $\mathrm{Ce} 4+$ to $\mathrm{Ce} 3+$ are accompanied by the creation of oxygen vacancies in the nanoparticle lattice [11].

The noble metal nanoparticles are found to be effective in scavenging oxygen based free radicals and exhibit promising catalytic activities for radical scavenging reactions [12]. A cerium oxide nanoparticle $\left(\mathrm{CeO}_{2} \mathrm{NP}\right)$ due to its electronic structure at the nanoscale leads to their antioxidant activity. Both large surface-area-tovolume ratio with the reduction in particle size and ability to reversibly 
switch between two state present on the surface result in the formation of oxygen defects in the crystal lattice that act as reactive site for free radical scavenging [13].

Nanoceria have shown numerous unique characteristics, such as biocompatibility, cellular, and nuclear membrane permeability, and are excellent agents for biological applications [14].

Functionalities can be added to nanomaterials by interfacing them with biological molecules or structures. Because of the size of nanomaterials is similar to that of most biological molecules and structures; therefore, nanomaterials can be useful for both in vivo and in vitro biomedical research and applications [15]. Recently, nanoparticles are gaining interest in the field of radioprotection as cerium oxide nanoparticles, yttrium oxide nanoparticles, carbon nanoparticles, etc. were found to possess antioxidant properties and several works have shown the ability of these nanoparticles to offer protection against radiation damages [16-18].

The DPPH method is rapid, simple, accurate and inexpensive assay for measuring the ability of different compounds to act as free radical scavengers or hydrogen donors, and to evaluate the antioxidant activity of foods and beverages [19].

DPPH (2, 2- diphenyl-1-picrylhydrazyl-hydrate) free radical method is an antioxidant assay based on electron-transfer that produces a violet solution in ethanol. This free radical, stable at room temperature, is reduced in the presence of an antioxidant molecule, giving rise to colorless ethanol solution. The use of the DPPH assay provides an easy and rapid way to evaluate antioxidants by spectrophotometry, so it can be useful to assess various products at a time [20]. In the present study
$\mathrm{CeO}_{2} \mathrm{NPs}$ have been analyzed for use against deleterious effects of gamma radiation throw in vitro scavenging activity study and in vivo study for radiation protection.

\section{Materials and methods Chemicals}

DPPH (2, 2- diphenyl-1picrylhydrazyl) and Cerium oxide (IV) nanoparticle $(40 \mathrm{~nm})$ is a pale yellowwhite powder, were supplied from Sigma Aldrich, Germany by united tetra group for medical and scientific supplies / Jordan.

\section{Animals}

Albino mice of 10-12weeks old, weighing $20-25 \mathrm{~g}$ was obtained from national center for control and pharmaceutical research. There were kept under standard condition of temperature and humidity in the biotechnology research center/Al-Nahrian University.

\section{Irradiation with gamma-radiation}

Irradiation was carried out using a

${ }^{137} \mathrm{Cs}$ gamma source at a dose rate of $0.2 \mathrm{rad} / \mathrm{hr}$ for water samples in an in vitro free radical scavenging study. For in vivo study, the animals were irradiated by ${ }^{137} \mathrm{Cs}$ gamma source of whole body exposure at a dose rate of $0.96 \mathrm{rad} / \mathrm{hr}$.

\section{Preparation of cerium oxide nanopowder solution}

The colloidal solution was prepared with different amounts of $\mathrm{CeO}_{2}$ nanopowder dispersed in $10 \mathrm{ml}$ dionozed (DIW) in a test tube. The solutions were shaken ultrasonically for $30 \mathrm{~min}$ without any suspension materials. The absorbance of solutions was measured by UV-Vis spectrophotometer. It was found that the best absorbance in the $0.001 \mathrm{~g} /$ $10 \mathrm{ml}$ concentration. The absorbance spectrum was recorded for the 
nanoparticles dispersed in water. Since water is used as a blank. A strong absorption below $400 \mathrm{~nm}$ was observed. Depending on this concentration, increasingly consecutive amounts from this solution were used to study the in vitro scavenging activity. The concentrations are ranged from 0.01 to $0.08 \mathrm{~g} / 1$.

\section{Determination of free radical scavenging activity}

The free radical scavenging capacity of cerium oxide nanoparticles was assayed using the modified DPPH method as reported previously [21]. DPPH $\quad(2, \quad 2-\quad$ diphenyl-1picrylhydrazyl) is a stable free radical and has been used as a model free radical compound to evaluate the effectiveness of antioxidant. Ethanolic solution of DPPH $(0.1 \mathrm{mM})$ was prepared and incubated at ambient temperature. To prevent free radical formation, $\mathrm{CeO}_{2} \mathrm{NPs}$ added to the water samples before and after irradiation process. Different concentrations $\quad(0.01-0.08 \mathrm{~g} / \mathrm{l}) \quad$ of $\mathrm{CeO}_{2} \mathrm{NPs}$ were added, in equal volume, to ethanolic DPPH solution and water sample. The mixture was shaken vigorously and allowed to stand for $30 \mathrm{~min}$ in the dark and the absorbance of all samples was monitored around $520 \mathrm{~nm}$. DPPH solution without nanoparticles served as the control. The percentage inhibition of DPPH was calculated according to the formula:

\% Inhibition $(\mathrm{I} \%)=\left[\left(\mathrm{A}_{\mathrm{c}}-\mathrm{A}_{\mathrm{s}}\right) / \mathrm{A}_{\mathrm{c}}\right] \times 100$

where $A_{c}$ is the absorbance of irradiated water with DPPH radical samples as a control, and $\mathrm{A}_{\mathrm{s}}$ is the absorbance of samples with different concentration of cerium oxide nanoparticles.

\section{Radioprotection ability of cerium oxide nanopartecles}

To protect the mice tissues due to radiation effect (whole body exposure) by the advantage of nanoparticles, the animals were divided into three groups. The first group is the normal without any irradiation and treatment, Second group is the animals exposed to gamma radiation of ${ }^{137} \mathrm{Cs}$ with equivalent dose $1.2 \mathrm{~Sv}$ and third group is the animals treated with $\mathrm{CeO}_{2} \mathrm{NPs}$ $(0.2 \mathrm{ml}$ equivalent to $50 \mu \mathrm{g} / \mathrm{ml})$ prior to whole body exposure with the same radiation equivalent dose.

\section{Histopathological examination}

The histological analysis over the oxidative stress after the irradiation was performed by examining the morphological changes in skin tissue induced by radiation, furthermore the analysis of the treatment with nanoparticles. The present study was carried out at the bio-technology research center/ Al-Nahrin University. After four day of irradiation and treatment, the animals were sacrificed. The tissue of interest, skin, were immediately fixed in $10 \%$ buffered neutral formalin solution, embedded in paraffin, and cut into $5-\mu \mathrm{m}$ thicksections. The fixed sections were stained for analysis using hematoxylin and eosin ( $\mathrm{H}$ and $\mathrm{E}$ ) staining. The sections were examined under light microscope and photomicrographs of the fixed skin tissues were obtained for study the microscopic morphology of the skin.

\section{Results and discussion \\ DPPH radical scavenging activity of $\mathrm{CeO}_{2} \mathrm{NPs}$}

There is not adequate study to assess the free radical scavenger activity with $\mathrm{CeO}_{2} \mathrm{NPs}$ by $\mathrm{DPPH}$ 
assay, although it has anti-oxidant properties. However the range of concentration which was used very restricted.

In order to investigate in vitro antioxidant activity of nanoceria, this work were carried out in two experiments with a range of $\mathrm{CeO}_{2} \mathrm{NPs}$ concentrations added to the samples before irradiation to prevent free radical formation and added after irradiation to scavenge free radicals and reduce their risk. DPPH is a stable organic free radical which is widely used as a substrate to evaluate antioxidant activity of different compound. DPPH absorbances at $525 \mathrm{~nm}$ for all samples for both experiments are sketched in Figs. 1 and 2. DPPH absorbance behavior as well as inhibition $\%$ as a function of increasing $\mathrm{CeO}_{2} \mathrm{NPs}$ concentration are compatible in both cases, the inhibition was found to be high in a concentration $0.05 \mathrm{~g} / \mathrm{l}$. However, higher than $0.06 \mathrm{~g} / \mathrm{l}$ concentration, their activity decreased markedly below the level observed for $0.05 \mathrm{~g} / \mathrm{l}$ (Figs.3a and 3b). The results showed reverse trend in absorbance and inhibition indicating this finite rang of concentration is suitable for scavenging free radicals. Antioxidant reacts with DPPH. which is stable free radical and convert it to 2, 2-diphenyl1-picrylhydrazine. The radical scavenging potential of the antioxidant was measured by the degree of discoloration. This assay provides information on the reactivity of the test compounds with a stable free radical. DPPH. gives a strong absorbance around $520 \mathrm{~nm}$ due to the odd electron. When the electron became paired off in the presence of free radical scavengers, the absorption decreases. The results of the present study show a strong antioxidative property of nanoceria. The reverse trend of $\mathrm{CeO}_{2}$ parameter, may be is due to the valence and defect structure of $\mathrm{CeO}_{2}$ is dynamic and may change spontaneously or in response to physical parameters such as temperature, oxygen partial pressure, and doping with other ions as well as an electrical field or surface stresses.

Table 1: Values of DPPH absorbance and inhibition \% with $\mathrm{CeO}_{2} \mathrm{NPs}$ concentrations.

\begin{tabular}{|c|c|c|c|c|}
\hline \multirow[t]{2}{*}{ Water samples } & \multicolumn{2}{|c|}{ Before irradiation } & \multicolumn{2}{|c|}{ After irradiation } \\
\hline & $\begin{array}{c}\text { DPPH } \\
\text { absorption }\end{array}$ & $\begin{array}{c}\text { Inhibition } \\
\%\end{array}$ & $\begin{array}{c}\text { DPPH } \\
\text { absorption }\end{array}$ & $\begin{array}{c}\text { Inhibition } \\
\%\end{array}$ \\
\hline Normal water & 0.6050 & & 0.6050 & \\
\hline irradiated & 0.6652 & & 0.6652 & \\
\hline $\begin{array}{c}\mathrm{CeO}_{2} \text { nanoparticles } \\
\text { concentration } \mathrm{g} / \mathrm{l}\end{array}$ & & & & \\
\hline 0.01 & 0.5810 & 12.65 & 0.5984 & 10.04 \\
\hline 0.02 & 0.5857 & 11.95 & 0.5932 & 10.82 \\
\hline 0.04 & 0.5246 & 21.13 & 0.5731 & 13.84 \\
\hline 0.05 & 0.5008 & 24.71 & 0.5241 & 21.21 \\
\hline 0.06 & 0.5341 & 19.70 & 0.6078 & 8.62 \\
\hline 0.07 & 0.6589 & 0.94 & 0.6139 & 7.71 \\
\hline 0.08 & 0.6635 & 0.25 & 0.6344 & 4.63 \\
\hline
\end{tabular}




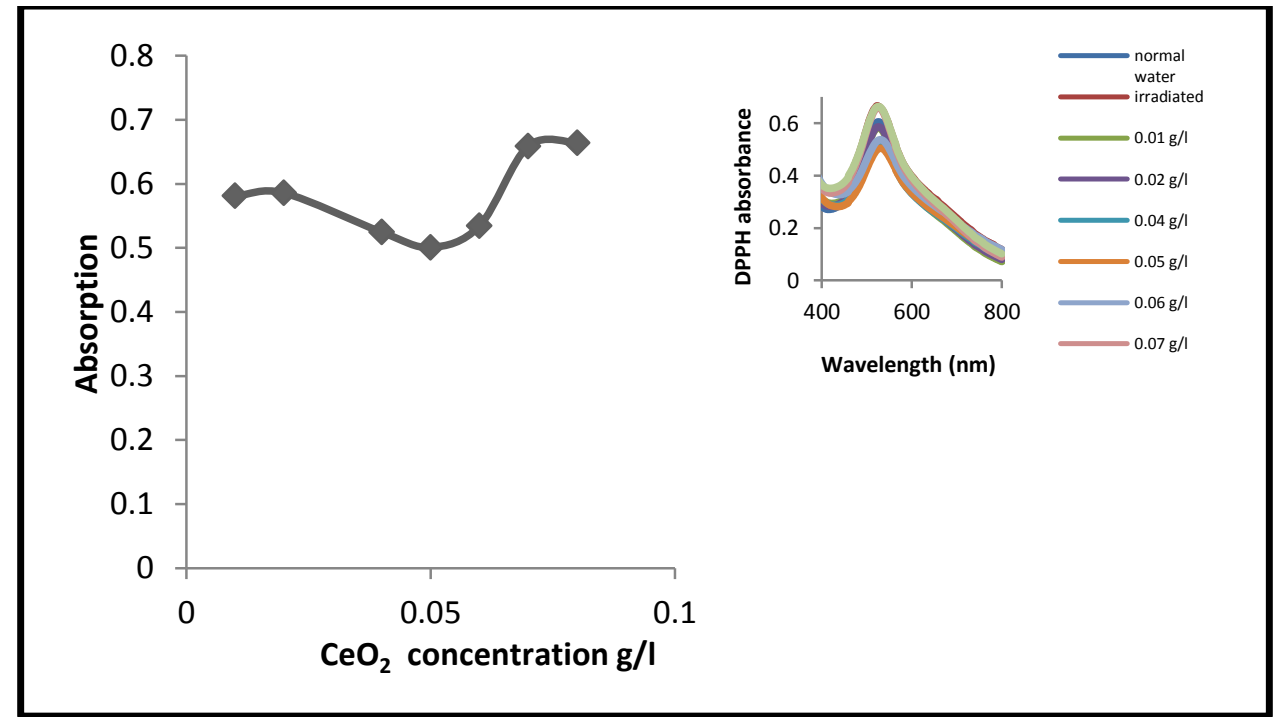

Fig. 1: DPPH absorption as a function of $\mathrm{CeO}_{2} \mathrm{NPs}$ concentration before irradiation.

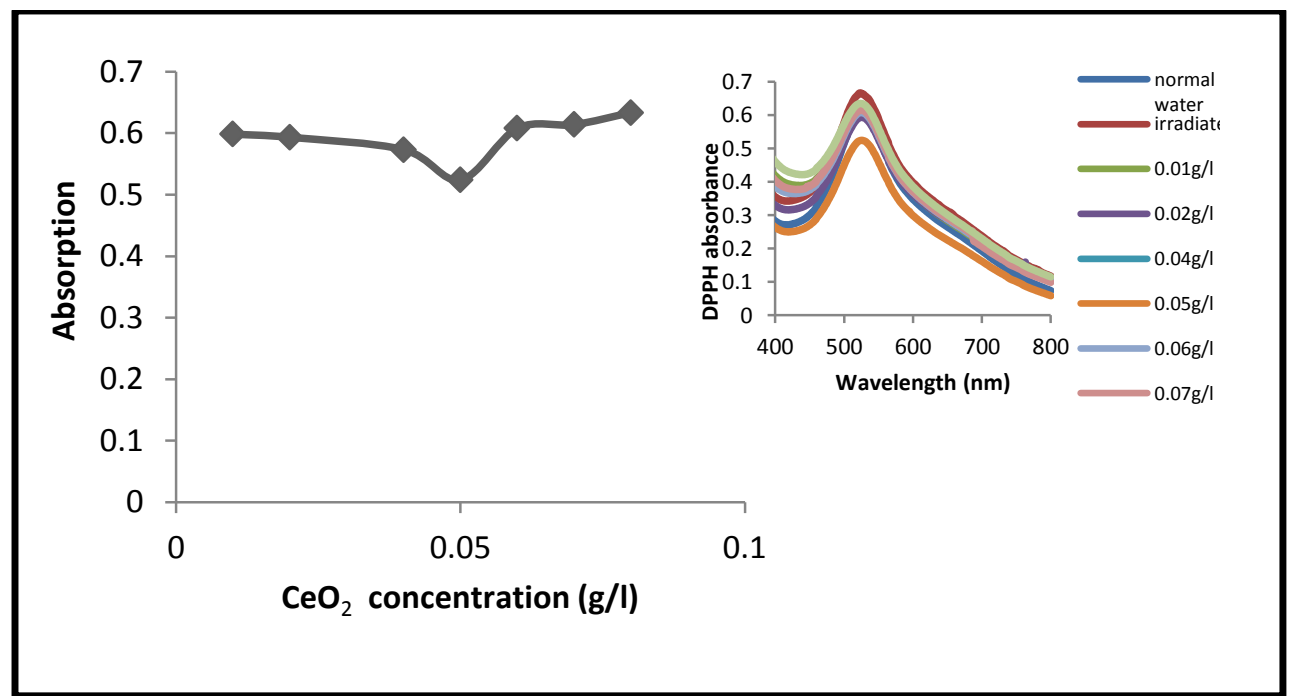

Fig. 2: DPPH absorption as a function of $\mathrm{CeO}_{2} \mathrm{NPs}$ concentration after irradiation.
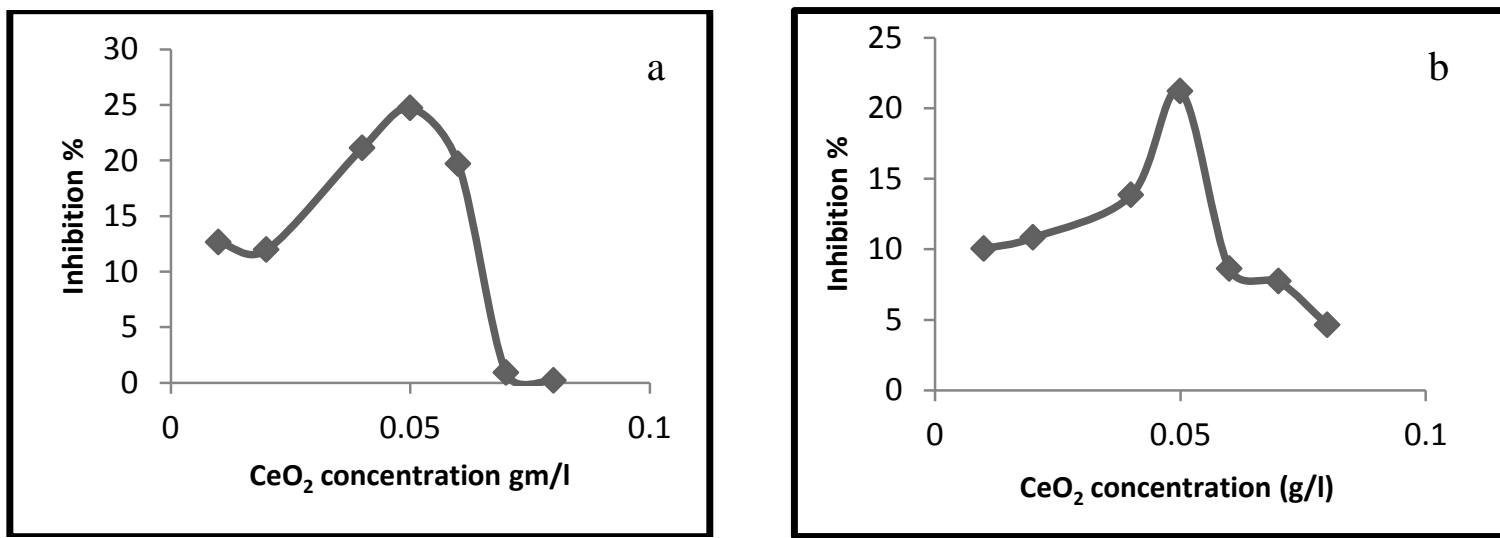

Fig. 3: Free radicals inhibition\% as a function of $\mathrm{CeO}_{2} \mathrm{NPs}$ concentration, a: before and b: after irradiation.

\section{Histopathological studies}

The in vivo study of radiation protection with cerium oxide nanoparticles by histological analysis was carried out over the skin tissues of albino mice. In order to examine the 
potency of cerium oxide nanoparticles to prevent the tissues from damage because of free radical formation. The results of histopathological skin section of normal animal demonstrate no clear lesions and abnormality feature in skin cells as shown in Fig. 4a. The whole body exposure of animals to gamma radiation with 1.2 Sv revealed apparent damage such as thickness of epidermis due to initiated proliferation of basal cells of epidermis with inflammatory cells infiltration in the dermis (Fig.4b). For the purpose of avoiding these damages in skin tissues caused by gamma radiation, the animals were treated with cerium oxide nanoparticles. The in vivo experiment of mice treated by $\mathrm{CeO}_{2}$ nanoparticles reinforces the conclusion that $\mathrm{CeO}_{2}$ nanoparticles confer tolerable protection from ionizing radiation as shown in Fig.(4.c). Thus $\mathrm{CeO}_{2} \mathrm{NPs}$ decrease the accumulation of ROS, and prevent the activation of the ROS-induced inflammatory, aggregation and proliferation of the skin cells, the antioxidant capability of $\mathrm{CeO}_{2}$ nanoparticles has been suggested as the key mechanism by which $\mathrm{CeO}_{2}$ nanoparticles as radioprotection.
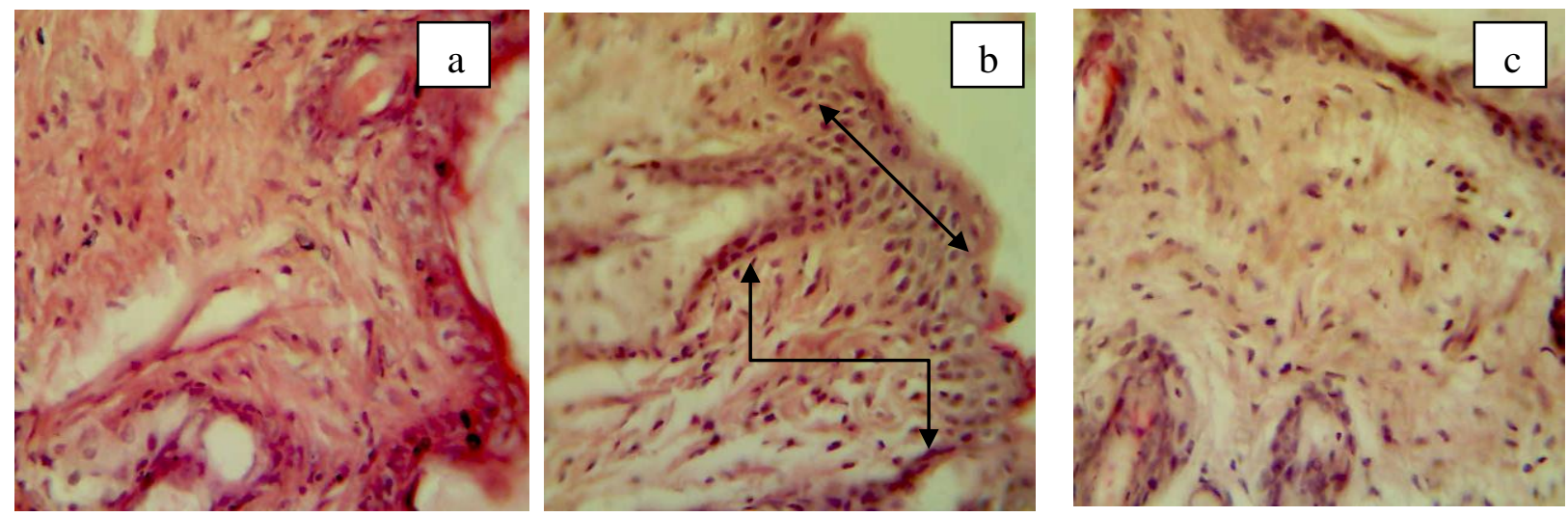

Fig. 4: Histopathological section in the skin of animal, a: normal skin without any lesions, $b$ : with whole body irradiation (1.2Sv) shows thickness of epidermis due to initiated proliferation of basal cells of epidermis $\underset{\text { with inflammatory cells infiltration in the }}{\text { dermis }}+(\mathrm{H} \& \mathrm{E}$ stain $400 \mathrm{X})$ and $\mathrm{c}:$ with whole body irradiation and treated with $\mathrm{CeO}_{2} \mathrm{NPS}^{\downarrow}$

\section{Conclusions}

The present results suggest the possibility of using $\mathrm{CeO}_{2} \mathrm{NPs}$ as an anti-oxidant agent by inhibition the formation of free radicals and scavenging free radicals from the irradiation water samples in a finite range of $\mathrm{CeO}_{2} \mathrm{NPs}$ concentration. The results of in vivo study suggest the possibility of using cerium oxide nanoparticles to protect animals from radiation damage due to its oxidative stress. Therefore the antioxidant behavior of nanoparticles makes them useful in therapy of many diseases caused by oxidative stress and potential candidates for medical applications.

\section{References}

[1] Australian Radiation Protection and Nuclear Safety Agency, Use of Radiation in Schools, Radiation Protection Series Publication No. 18, (2012).

[2] K. M. Prise, Occupational Medicine, 56 (2006) 156-161.

[3] E. J. Hall and A. J. Giaccia, "Radiobiology for the radiologist", Lippincott Williams and Wilikins, New York, (2006).

[4] IAEA, Radiation Biology, A Handbook for Teachers and Students, 
Vienna, IAEA-TCS-42, Printed by the IAEA in Austria, (2010).

[5] D. K. Chandrasekharan, P. K. Khanna, T. V. Kagiya, C. K. K. Nair, Cancer Biotherapy and Radiopharmaceuticals, 26, 2 (2011) 249-257.

[6] M. E. Barbinta Patrascu, A. Cojocariu, L. Tugulea, N. M. Badea, I. Lacatusu, A. Meghea, J. Optoelectron Adv. Mater, 13, 9 (2011) 1153-1158.

[7] K. N. Thakkar, S. S. Mhatre, R. Y. Parikh, Nanomed. Nanotechnol. Biol. Med., 6, 2 (2010) 257-262

[8] I. R. Bunghez, M. E. Barbinta Patrascu, N. Badea, S. M. Doncea, A. Popescu, R. M. Ion, J. Optoelectron Adv. Mater, 14, 11 (2012) 1016-1022.

[9] C. Korsvik, S. Patil, S. Seal, W. T. Self, Chemical Communications, 14, 10 (2007) 1056-1058.

[10] E. G. Heckert, A. S.Karakoti, S. Seal, W. T. Self, Biomaterials, 29, 18 (2008) 2705-2709.

[11] R. D. Robinson, J. E. Spanier, F. Zhang, I.P. Herman, Journal of Applied Physics, 92, 4 (2002) 19361941

[12] K. Esumi, N. Takei, T. Yoshimura, Colloids and Surfaces B: Biointerfaces, 32, 2 (2003) 117-123.

[13] N. M. Kobyliak, T. M. Falalyeyeva, O. G. Kuryk, T. V.
Beregova, P. M. Bodnar, N. M. Zholobak, O. B. Shcherbakov, R. V. Bubnov, M. Ya Spivak, EPMA Journal, 6, 12 (2015) 1-22.

[14] J. Chen, S. Patil, S. Seal, J. F. McGinnis, Nature Nanotechnology, 1, 2 (2006) 142-150.

[15] P. Boisseau and B. Loubaton, Comptes Rendus Physique, 12, 7 (2011) 620-636.

[16] B. A. Rzigalinski, Technol. Cancer Res. Treat., 4 (2005) 651-659.

[17] S. S. Ali, J. I. Hardt, K. L. Quick, J. S. Kim-Han, B. F. Erlanger, T. T. Huang, C. J. Epstein, L. L. Dugan, Free Radic. Biol. Med., 37 (2004) 1191-1202.

[28] D. Schubert, R. Dargusch, J. Raitano, S. W. Chan, Biochem Biophys Res Commun, 342 (2006) 86-91.

[29] G. Marinova and V. Batchvarov, Bulgarian Journal of Agricultural Science, 17, 1 (2011) 11-24.

[20] E. J. Garcia, T. Oldoni, S. M. De Alencar, A. Reis, A. D. Loguercio, R. Grande, Braz. Dent. J., 23, 1 (2012) 22-27.

[21] C. Dipankar, S. Murugan, Colloids Surf. Bioi., B 98 (2012) 112119. 